\title{
Anova Analysis
}

\section{Effect of nanoparticles on Viscosity (Single factor Anova)}

\begin{tabular}{|c|c|c|c|c|}
\hline $\begin{array}{l}\text { Viscosity } \\
\text { Data }\end{array}$ & & & & \\
\hline & $\mathrm{BN}-1$ & $\mathrm{BN}-2$ & $\mathrm{BN}-3$ & BN-4 \\
\hline & 35.8385 & 56.8686 & 88.6152 & 358.803 \\
\hline & 41.8452 & 71.2642 & 107.813 & 430.306 \\
\hline & 41.5968 & 75.2453 & 107.086 & 421.439 \\
\hline & 38.0133 & 70.3442 & 95.2645 & 379.512 \\
\hline & 32.7847 & 60.7477 & 79.6346 & 191.655 \\
\hline & 26.8213 & 49.5794 & 64.5794 & 152.808 \\
\hline & 20.8977 & 38.2744 & 52.2744 & 132.428 \\
\hline & 15.4897 & 28.2901 & 38.2901 & 105.752 \\
\hline & 11.0291 & 20.4801 & 30.4801 & 80.417 \\
\hline & 7.59006 & 14.456 & 22.456 & 55.2177 \\
\hline & 5.39956 & 10.0763 & 17.0763 & 40.321 \\
\hline & 3.79187 & 7.02252 & 13.02252 & 27.8654 \\
\hline & 2.64712 & 4.88333 & 9.88333 & 18.3061 \\
\hline & 1.87393 & 3.41064 & 7.41064 & 12.46176 \\
\hline & 1.31438 & 2.35448 & 5.35448 & 8.80828 \\
\hline & 0.924569 & 1.58839 & 3.58839 & 5.96659 \\
\hline & 0.657396 & 1.06839 & 2.56839 & 3.87373 \\
\hline & 0.472726 & 0.730791 & 1.730791 & 2.75318 \\
\hline & 0.34268 & 0.507009 & 1.207009 & 1.90301 \\
\hline & 0.250903 & 0.355308 & 0.855308 & 1.300067 \\
\hline & 0.185238 & 0.251407 & 0.651407 & 1.000578 \\
\hline & 0.137175 & 0.179952 & 0.479952 & 0.751416 \\
\hline & 0.101096 & 0.13128 & 0.33128 & 0.502102 \\
\hline & 0.074568 & 0.098144 & 0.248144 & 0.355317 \\
\hline & 0.055655 & 0.075799 & 0.185799 & 0.252327 \\
\hline & 0.045506 & 0.058996 & 0.148996 & 0.20186 \\
\hline & 0.039223 & 0.048073 & 0.118073 & 0.156416 \\
\hline & 0.034213 & 0.036312 & 0.096312 & 0.10619 \\
\hline & 0.027965 & 0.031954 & 0.081954 & 0.088652 \\
\hline & 0.024482 & 0.028482 & 0.068482 & 0.078812 \\
\hline & 0.023514 & 0.026242 & 0.066242 & 0.066768 \\
\hline
\end{tabular}


Anova: Single Factor

SUMMARY

\begin{tabular}{|c|c|c|c|c|}
\hline Groups & Count & Sum & Average & Variance \\
\hline BN-1 & 31 & 290.3301 & 9.365488 & 206.6434 \\
\hline $\mathrm{BN}-2$ & 31 & 518.5138 & 16.72625 & 649.6218 \\
\hline $\mathrm{BN}-3$ & 31 & 751.6671 & 24.24733 & 1286.846 \\
\hline $\mathrm{BN}-4$ & 31 & 2435.457 & 78.56314 & 18185.34 \\
\hline
\end{tabular}

ANOVA

\begin{tabular}{lcrcccc}
\hline \multicolumn{1}{c}{ Source of Variation } & \multicolumn{1}{c}{ SS } & $d f$ & \multicolumn{1}{c}{ MS } & $F$ & P-value & F crit \\
\hline Between Groups & 92182.68 & 3 & 30727.56 & 6.046217 & 0.00072 & 2.680168 \\
Within Groups & 609853.5 & 120 & 5082.113 & & & \\
& & & & & & \\
Total & 702036.2 & 123 & & & & \\
\hline
\end{tabular}

Interpretation

The above table shows many variable such as $\mathrm{F}, \mathrm{F}_{\text {crit }}$, and $\mathrm{P}$-value. Here the F (6.046217) value is greater than $\left(\mathrm{F}_{\text {crit }}\right)(2.680168)$ value and $p$-value $(0.00072)$ is less than 0.05 value used in the Anova analysis shows that data is significantly different from each other (So, we can reject the null hypothesis). As we can see the variance of $\mathrm{BN}-1, \mathrm{BN}-2, \mathrm{BN}-3, \mathrm{BN}-4$ are way different from each other, the different values of variance and very small value of $\mathrm{P}$ indicate that viscosities are different from each other. It was also observed that by increasing the nanoparticles concentration, the viscosities also increased.

\section{Effect of Polymer on Viscosity (Single factor Anova)}

\begin{tabular}{|l|l|l|l|l|}
\hline Viscosity Data & & & & \\
\hline & BP-1 & BP-2 & BP-3 & BP-4 \\
\hline & 382.027 & 485.446 & 587.173 & 937.798 \\
\hline & 483.314 & 577.072 & 747.746 & 1202.12 \\
\hline & 497.212 & 493.682 & 788.158 & 1268.59 \\
\hline
\end{tabular}




\begin{tabular}{|l|l|l|l|l|}
\hline & 455.985 & 314.847 & 749.346 & 1129.57 \\
\hline & 245.004 & 202.792 & 560.918 & 671.386 \\
\hline & 146.26 & 135.361 & 330.78 & 406.484 \\
\hline & 99.8241 & 88.2233 & 225.819 & 270.617 \\
\hline & 73.1596 & 58.5908 & 169.336 & 193.281 \\
\hline & 53.9956 & 39.9205 & 119.601 & 144.355 \\
\hline & 36.3277 & 29.009 & 77.1113 & 100.281 \\
\hline & 23.2909 & 20.8395 & 48.5255 & 68.7755 \\
\hline & 15.1742 & 14.7507 & 30.4727 & 44.5108 \\
\hline & 9.77317 & 9.6448 & 19.7495 & 28.6249 \\
\hline & 6.08334 & 6.37099 & 13.1786 & 18.7823 \\
\hline & 3.85864 & 4.43055 & 8.60542 & 12.3557 \\
\hline & 2.3954 & 2.81354 & 5.28846 & 8.25071 \\
\hline & 1.5273 & 1.79879 & 3.29318 & 5.75336 \\
\hline & 0.995633 & 1.12641 & 2.08328 & 3.89643 \\
\hline & 0.663577 & 0.717421 & 1.33481 & 2.28323 \\
\hline & 0.447749 & 0.465801 & 0.859112 & 1.39361 \\
\hline & 0.302104 & 0.310916 & 0.556894 & 0.894376 \\
\hline & 0.194396 & 0.212216 & 0.36512 & 0.574196 \\
\hline & 0.118498 & 0.139992 & 0.24306 & 0.369803 \\
\hline & 0.07907 & 0.084226 & 0.165449 & 0.242178 \\
\hline & 0.056804 & 0.054964 & 0.115921 & 0.161049 \\
\hline & 0.04214 & 0.039152 & 0.083806 & 0.108443 \\
\hline & 0.03228 & 0.028775 & 0.062862 & 0.076802 \\
\hline & 0.025486 & 0.021588 & 0.048165 & 0.05601 \\
\hline & 0.021384 & 0.017447 & 0.038088 & 0.041973 \\
\hline & 0.018517 & 0.01465 & 0.031653 & 0.032945 \\
\hline & 0.017773 & 0.013955 & 0.029833 & 0.031225 \\
\hline & & & & \\
\hline
\end{tabular}

Anova: Single

Factor

SUMMARY

\begin{tabular}{lrrrr}
\hline Groups & Count & \multicolumn{1}{c}{ Sum } & Average & Variance \\
\hline BP-1 & 31 & 2538.227 & 81.8783 & 24291.82 \\
BP-2 & 31 & 2488.84 & 80.28516 & 26187.35 \\
BP-3 & 31 & 4491.12 & 144.8748 & 65462.99 \\
BP-4 & 31 & 6521.698 & 210.3773 & 153447.5 \\
\hline
\end{tabular}

ANOVA 


\begin{tabular}{lcrcccc}
\hline Source of Variation & \multicolumn{1}{c}{$S S$} & $d f$ & $M S$ & $F$ & P-value & F crit \\
\hline Between Groups & 355488.5 & 3 & 118496.2 & 1.759476 & 0.158605 & 2.680168 \\
Within Groups & 8081689 & 120 & 67347.41 & & & \\
& & & & & & \\
Total & 8437178 & 123 & & & & \\
\hline
\end{tabular}

\section{Interpretation}

The above table shows many variable such as F, $F_{\text {crit }}$, and P-value. Here the F (1.759476) value is less than $\left(\mathrm{F}_{\text {crit }}\right)(2.680168)$ value and $\mathrm{p}$-value $(0.158605)$ is greater than 0.05 value used in the Anova analysis shows that data is not statistically different from each other (So, we cannot reject the null hypothesis). As we can see the variance of BP-1, BP-2, BP-3, BP-4 are way different from each other, the different values of variance indicate that viscosities are different from each other. It was also observed that by increasing the polymer concentration, the viscosities also increased for drilling fluid formulations.

\section{Effect of nanoparticles and polymer on viscosity (Single factor Anova)}

\begin{tabular}{|c|c|c|c|c|}
\hline $\begin{array}{c}\text { Viscosity } \\
\text { Data }\end{array}$ & BPN-1 & BPN-2 & BPN-3 & BPN-4 \\
\hline & 425.397 & 690.373 & 1191.8 & 1358.27 \\
\hline & 466.352 & 895.722 & 1528.13 & 1748.46 \\
\hline & 445.647 & 966.808 & 1618.79 & 1860.73 \\
\hline & 399.183 & 949.498 & 1518.08 & 1774.5 \\
\hline & 344.446 & 844.006 & 1206.95 & 1457.02 \\
\hline & 288.776 & 483.011 & 729.29 & 868.717 \\
\hline & 228.896 & 318.665 & 467.098 & 563.068 \\
\hline & 166.128 & 233.631 & 325.902 & 392.424 \\
\hline & 75.582 & 160.806 & 229.306 & 259.813 \\
\hline & 45.0853 & 105.531 & 145.78 & 166.655 \\
\hline & 25.8605 & 68.1426 & 94.2424 & 107.163 \\
\hline & 18.8006 & 43.7365 & 56.3741 & 70.8138 \\
\hline & 10.6023 & 28.6641 & 35.1708 & 47.6706 \\
\hline
\end{tabular}




\begin{tabular}{|c|c|c|c|c|}
\hline & 6.86312 & 19.1889 & 24.009 & 31.3688 \\
\hline & 4.6126 & 12.4548 & 15.1398 & 21.9346 \\
\hline & 3.30417 & 7.57053 & 10.3191 & 14.7597 \\
\hline & 2.31242 & 4.78545 & 7.16873 & 9.47968 \\
\hline & 1.62423 & 3.04175 & 4.96436 & 5.55952 \\
\hline & 1.15226 & 1.94492 & 3.27976 & 3.44062 \\
\hline & 0.81614 & 1.25747 & 1.99896 & 2.19366 \\
\hline & 0.576263 & 0.814402 & 1.26809 & 1.4142 \\
\hline & 0.410933 & 0.526987 & 0.823563 & 0.917081 \\
\hline & 0.297521 & 0.347024 & 0.539302 & 0.596902 \\
\hline & 0.21051 & 0.229795 & 0.35635 & 0.393828 \\
\hline & 0.148421 & 0.158039 & 0.239025 & 0.262266 \\
\hline & 0.105111 & 0.113436 & 0.164592 & 0.175747 \\
\hline & 0.077146 & 0.084262 & 0.116687 & 0.121967 \\
\hline & 0.058453 & 0.064307 & 0.084479 & 0.088079 \\
\hline & 0.045153 & 0.050223 & 0.06228 & 0.065077 \\
\hline & 0.03961 & 0.040687 & 0.047301 & 0.049388 \\
\hline & 0.038916 & 0.038643 & 0.044588 & 0.046519 \\
\hline
\end{tabular}

Anova: Single Factor

SUMMARY

\begin{tabular}{lrrrr}
\hline \multicolumn{1}{c}{ Groups } & Count & \multicolumn{1}{c}{ Sum } & Average & Variance \\
\hline BPN-1 & 31 & 2963.449 & 95.59512 & 25470.01 \\
BPN-2 & 31 & 5841.306 & 188.4292 & 105376.4 \\
BPN-3 & 31 & 9217.539 & 297.34 & 278033.1 \\
BPN-4 & 31 & 10768.17 & 347.3604 & 374574.3 \\
\hline
\end{tabular}

ANOVA

Source of

Variation

SS

$d f$

Between Groups 1180539

Within Groups 23503618

Total

24684157

123 


\section{Interpretation}

The above table shows many variable such as F, $F_{\text {crit }}$, and P-value. Here the F (2.009119) value is less than $\left(F_{\text {crit }}\right)(2.680168)$ value and p-value $(0.116315)$ is greater than 0.05 value used in the Anova analysis shows that data is not statistically different from each other (So, we cannot reject the null hypothesis). As we can see the variance of BPN-1, BPN-2, BPN-3, BPN-4 are way different from each other, the different values of variance indicate that viscosities are different from each other. It was also observed that by increasing the polymer and nanoparticles concentration, the viscosities also increased for drilling fluid formulations.

\section{Synergistic effect of polymer and nanoparticles on viscosity data (Anova: Two-Factor with Replication)}

\begin{tabular}{|c|c|c|c|c|}
\hline Group & 1 & 2 & 3 & 4 \\
\hline BN & 35.8385 & 56.8686 & 88.6152 & 358.803 \\
\hline & 41.8452 & 71.2642 & 107.813 & 430.306 \\
\hline & 41.5968 & 75.2453 & 107.086 & 421.439 \\
\hline & 38.0133 & 70.3442 & 95.2645 & 379.512 \\
\hline & 32.7847 & 60.7477 & 79.6346 & 191.655 \\
\hline & 26.8213 & 49.5794 & 64.5794 & 152.808 \\
\hline & 20.8977 & 38.2744 & 52.2744 & 132.428 \\
\hline & 15.4897 & 28.2901 & 38.2901 & 105.752 \\
\hline & 11.0291 & 20.4801 & 30.4801 & 80.417 \\
\hline & 7.59006 & 14.456 & 22.456 & 55.2177 \\
\hline & 5.39956 & 10.0763 & 17.0763 & 40.321 \\
\hline & 3.79187 & 7.02252 & 13.02252 & 27.8654 \\
\hline & 2.64712 & 4.88333 & 9.88333 & 18.3061 \\
\hline & 1.87393 & 3.41064 & 7.41064 & 12.46176 \\
\hline & 1.31438 & 2.35448 & 5.35448 & 8.80828 \\
\hline & 0.924569 & 1.58839 & 3.58839 & 5.96659 \\
\hline & 0.657396 & 1.06839 & 2.56839 & 3.87373 \\
\hline & 0.472726 & 0.730791 & 1.730791 & 2.75318 \\
\hline & 0.34268 & 0.507009 & 1.207009 & 1.90301 \\
\hline & 0.250903 & 0.355308 & 0.855308 & 1.300067 \\
\hline & & & & \\
\hline
\end{tabular}




\begin{tabular}{|c|c|c|c|c|}
\hline & 0.185238 & 0.251407 & 0.651407 & 1.000578 \\
\hline & 0.137175 & 0.179952 & 0.479952 & 0.751416 \\
\hline & 0.101096 & 0.13128 & 0.33128 & 0.502102 \\
\hline & 0.074568 & 0.098144 & 0.248144 & 0.355317 \\
\hline & 0.055655 & 0.075799 & 0.185799 & 0.252327 \\
\hline & 0.045506 & 0.058996 & 0.148996 & 0.20186 \\
\hline & 0.039223 & 0.048073 & 0.118073 & 0.156416 \\
\hline & 0.034213 & 0.036312 & 0.096312 & 0.10619 \\
\hline & 0.027965 & 0.031954 & 0.081954 & 0.088652 \\
\hline & 0.024482 & 0.028482 & 0.068482 & 0.078812 \\
\hline & 0.023514 & 0.026242 & 0.066242 & 0.066768 \\
\hline \multirow[t]{30}{*}{$\mathrm{BP}$} & 382.027 & 485.446 & 587.173 & 937.798 \\
\hline & 483.314 & 577.072 & 747.746 & 1202.12 \\
\hline & 497.212 & 493.682 & 788.158 & 1268.59 \\
\hline & 455.985 & 314.847 & 749.346 & 1129.57 \\
\hline & 245.004 & 202.792 & 560.918 & 671.386 \\
\hline & 146.26 & 135.361 & 330.78 & 406.484 \\
\hline & 99.8241 & 88.2233 & 225.819 & 270.617 \\
\hline & 73.1596 & 58.5908 & 169.336 & 193.281 \\
\hline & 53.9956 & 39.9205 & 119.601 & 144.355 \\
\hline & 36.3277 & 29.009 & 77.1113 & 100.281 \\
\hline & 23.2909 & 20.8395 & 48.5255 & 68.7755 \\
\hline & 15.1742 & 14.7507 & 30.4727 & 44.5108 \\
\hline & 9.77317 & 9.6448 & 19.7495 & 28.6249 \\
\hline & 6.08334 & 6.37099 & 13.1786 & 18.7823 \\
\hline & 3.85864 & 4.43055 & 8.60542 & 12.3557 \\
\hline & 2.3954 & 2.81354 & 5.28846 & 8.25071 \\
\hline & 1.5273 & 1.79879 & 3.29318 & 5.75336 \\
\hline & 0.995633 & 1.12641 & 2.08328 & 3.89643 \\
\hline & 0.663577 & 0.717421 & 1.33481 & 2.28323 \\
\hline & 0.447749 & 0.465801 & 0.859112 & 1.39361 \\
\hline & 0.302104 & 0.310916 & 0.556894 & 0.894376 \\
\hline & 0.194396 & 0.212216 & 0.36512 & 0.574196 \\
\hline & 0.118498 & 0.139992 & 0.24306 & 0.369803 \\
\hline & 0.07907 & 0.084226 & 0.165449 & 0.242178 \\
\hline & 0.056804 & 0.054964 & 0.115921 & 0.161049 \\
\hline & 0.04214 & 0.039152 & 0.083806 & 0.108443 \\
\hline & 0.03228 & 0.028775 & 0.062862 & 0.076802 \\
\hline & 0.025486 & 0.021588 & 0.048165 & 0.05601 \\
\hline & 0.021384 & 0.017447 & 0.038088 & 0.041973 \\
\hline & 0.018517 & 0.01465 & 0.031653 & 0.032945 \\
\hline
\end{tabular}




\begin{tabular}{|c|c|c|c|c|}
\hline & 0.017773 & 0.013955 & 0.029833 & 0.031225 \\
\hline BPN & 425.397 & 690.373 & 1191.8 & 1358.27 \\
\hline & 466.352 & 895.722 & 1528.13 & 1748.46 \\
\hline & 445.647 & 966.808 & 1618.79 & 1860.73 \\
\hline & 399.183 & 949.498 & 1518.08 & 1774.5 \\
\hline & 344.446 & 844.006 & 1206.95 & 1457.02 \\
\hline & 288.776 & 483.011 & 729.29 & 868.717 \\
\hline & 228.896 & 318.665 & 467.098 & 563.068 \\
\hline & 166.128 & 233.631 & 325.902 & 392.424 \\
\hline & 75.582 & 160.806 & 229.306 & 259.813 \\
\hline & 45.0853 & 105.531 & 145.78 & 166.655 \\
\hline & 25.8605 & 68.1426 & 94.2424 & 107.163 \\
\hline & 18.8006 & 43.7365 & 56.3741 & 70.8138 \\
\hline & 10.6023 & 28.6641 & 35.1708 & 47.6706 \\
\hline & 6.86312 & 19.1889 & 24.009 & 31.3688 \\
\hline & 4.6126 & 12.4548 & 15.1398 & 21.9346 \\
\hline & 3.30417 & 7.57053 & 10.3191 & 14.7597 \\
\hline & 2.31242 & 4.78545 & 7.16873 & 9.47968 \\
\hline & 1.62423 & 3.04175 & 4.96436 & 5.55952 \\
\hline & 1.15226 & 1.94492 & 3.27976 & 3.44062 \\
\hline & 0.81614 & 1.25747 & 1.99896 & 2.19366 \\
\hline & 0.576263 & 0.814402 & 1.26809 & 1.4142 \\
\hline & 0.410933 & 0.526987 & 0.823563 & 0.917081 \\
\hline & 0.297521 & 0.347024 & 0.539302 & 0.596902 \\
\hline & 0.21051 & 0.229795 & 0.35635 & 0.393828 \\
\hline & 0.148421 & 0.158039 & 0.239025 & 0.262266 \\
\hline & 0.105111 & 0.113436 & 0.164592 & 0.175747 \\
\hline & 0.077146 & 0.084262 & 0.116687 & 0.121967 \\
\hline & 0.058453 & 0.064307 & 0.084479 & 0.088079 \\
\hline & 0.045153 & 0.050223 & 0.06228 & 0.065077 \\
\hline 0.03961 & 0.040687 & 0.047301 & 0.049388 \\
\hline 0.038916 & 0.038643 & 0.044588 & 0.046519 \\
\hline & & & & \\
\hline & & & \\
\hline & &
\end{tabular}

Anova: Two-Factor With Replication

\begin{tabular}{|c|c|c|c|c|c|}
\hline SUMMARY & 1 & 2 & 3 & 4 & Total \\
\hline Count & 31 & 31 & 31 & 31 & 124 \\
\hline Sum & 290.330129 & 518.513798 & 751.6670982 & 2435.45725 & 3995.968 \\
\hline Average & 9.36548803 & 16.7262516 & 24.24732575 & 78.5631372 & 32.22555 \\
\hline
\end{tabular}


$\begin{array}{llllll}\text { Variance } & 206.64344 & 649.621778 & 1286.845693 & 18185.3401 & 5707.611\end{array}$

\begin{tabular}{lrrrrr}
\multicolumn{1}{c}{$B P$} & \multicolumn{5}{c}{} \\
\hline Count & 31 & 31 & 31 & 31 & 124 \\
Sum & 2538.22736 & 2488.83998 & 4491.119713 & 6521.69754 & 16039.88 \\
Average & 81.8783019 & 80.2851608 & 144.8748295 & 210.37734 & 129.3539 \\
Variance & 24291.8248 & 26187.3526 & 65462.9883 & 153447.477 & 68594.94
\end{tabular}

\begin{tabular}{lrrrrr}
\multicolumn{1}{c}{$B P N$} & \multicolumn{3}{c}{} \\
\hline Count & 31 & 31 & 31 & 31 & 124 \\
Sum & 2963.44868 & 5841.30583 & 9217.539267 & 10768.172 & 28790.47 \\
Average & 95.5951186 & 188.42922 & 297.3399764 & 347.360388 & 232.1812 \\
Variance & 25470.0106 & 105376.448 & 278033.1294 & 374574.332 & 200684.2
\end{tabular}

\begin{tabular}{lrrrr}
\multicolumn{1}{c}{ Total } & \multicolumn{5}{c}{} \\
\hline Count & 93 & 93 & 93 & 93 \\
Sum & 5792.00617 & 8848.65961 & 14460.32608 & 19725.3268 \\
Average & 62.2796362 & 95.1468775 & 155.4873772 & 212.100288 \\
Variance & 17740.939 & 48191.7691 & 125051.193 & 190285.412
\end{tabular}

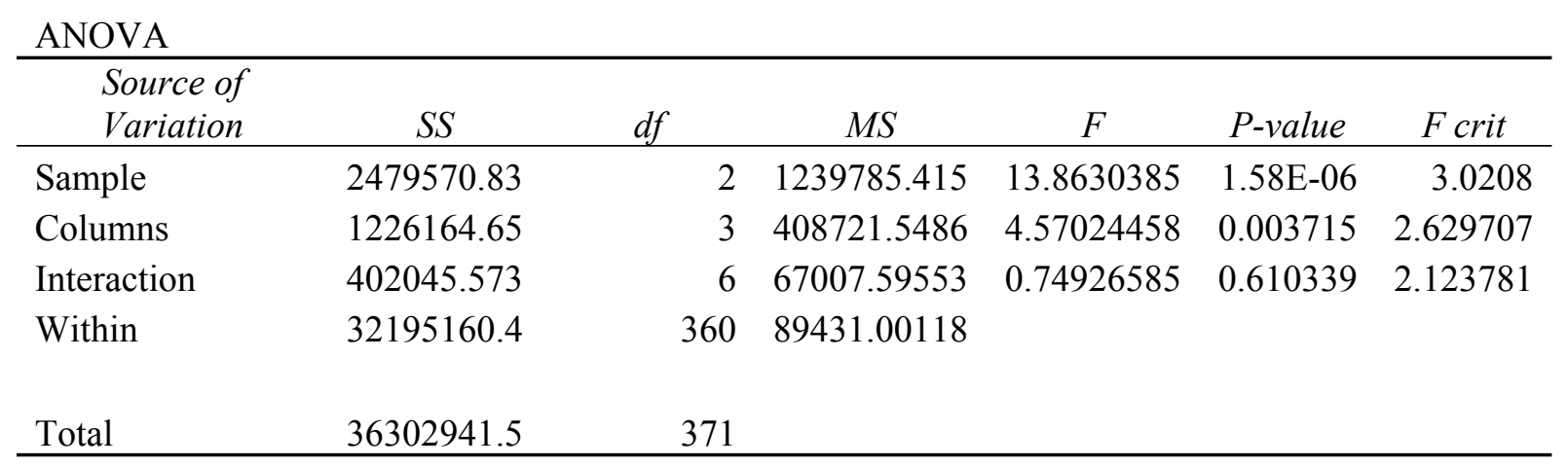

\section{Interpretation}

The synergistic effect of nanoparticles and polymer on rheological properties (viscosities) was observed by two way Anova. The F value 13.8 of Sample is way higher than the F (critical) 3.0208 and $\mathrm{P}$ value is also very small compared to the $\mathrm{P}$ value used in the Anova analysis (Both the parameters indicates the rejection of null hypothesis). The variation in $\mathrm{F}$ and $\mathrm{P}$ values of Sample 
indicates that the data BN (nanoparticles effect), BP (polymer's effect on viscosity), BNP (synergistic impact of nanoparticle and polymer) are significantly different from each other. It also indicates that the addition of nanoparticles, polymer and combined addition of (polymer and nanoparticles) results in the higher values of viscosities.

\section{Fluid loss data (Anova: Single Factor)}

\begin{tabular}{|c|c|c|c|c|}
\hline $\begin{array}{c}\text { Fluid loss } \\
\text { Data }\end{array}$ & & & & \\
\hline & B & BN-4 & BP-4 & BPN-4 \\
\hline & 4.2 & 2.2 & 1.8 & 0.5 \\
\hline & 11 & 6.9 & 5.2 & 2.8 \\
\hline & 16.1 & 11.1 & 7.9 & 4.8 \\
\hline & 18.5 & 13.6 & 9.4 & 6.1 \\
\hline & 20.8 & 15.5 & 10.5 & 6.9 \\
\hline & 22.8 & 15.9 & 10.7 & 7.1 \\
\hline
\end{tabular}

Anova: Single Factor

SUMMARY

\begin{tabular}{lrrrr}
\hline \multicolumn{1}{c}{ Groups } & Count & \multicolumn{1}{c}{ Sum } & Average & Variance \\
\hline B & 6 & 93.4 & 15.56667 & 47.73067 \\
BN-4 & 6 & 65.2 & 10.86667 & 29.03467 \\
BP-4 & 6 & 45.5 & 7.583333 & 12.14967 \\
BPN-4 & 6 & 28.2 & 4.7 & 6.764 \\
\hline
\end{tabular}

ANOVA

\begin{tabular}{lrrrccc}
\hline \multicolumn{1}{c}{$\begin{array}{l}\text { Source of } \\
\text { Variation }\end{array}$} & \multicolumn{1}{c}{ SS } & \multicolumn{1}{c}{ df } & \multicolumn{1}{c}{ MS } & \multicolumn{1}{c}{ F } & P-value & F crit \\
\hline Between Groups & 391.5446 & 3 & 130.5149 & 5.456364 & 0.006611 & 3.098391 \\
Within Groups & 478.395 & 20 & 23.91975 & & & \\
& & & & & & \\
Total & 869.9396 & 23 & & & & \\
\hline
\end{tabular}




\section{Interpretation}

The above table shows many variable such as F, $\mathrm{F}_{\text {crit }}$, and P-value. Here the F (5.456364) value is greater than $\left(\mathrm{F}_{\text {crit }}\right)(3.098391)$ value and p-value $(0.006611)$ is less than 0.05 value used in the Anova analysis shows that data is significantly different from each other (So, we can reject the null hypothesis). As we can see the variance of $\mathrm{B}, \mathrm{BN}-4, \mathrm{BP}-4, \mathrm{BPN}-4$ are way different from each other, the different values of variance and very small value of $\mathrm{P}$ indicate that fluid loss volumes are different from each other. It also showed that the addition of nanoparticles, polymer and combined addition of polymer and nanoparticles results in way different data (variance decreases) from $\mathrm{B}$, to BPN-4 indicating the decrease in the fluid loss. 


\section{Comparison of rheological, filtration and shale inhibition properties with PAM based drilling fluid}

The following data is presented to show the comparison of prepared drilling fluid formulations with PAM based drilling fluid at $25^{\circ} \mathrm{C}$. The PAM based drilling fluid $(\mathrm{B} / \mathrm{PAM} / \mathrm{N})$ was prepared by mixing 5 wt.\% bentonite, $0.1 \mathrm{wt} \%$ polyacrylamide having similar molecular weight as associative polymer, 1 wt.\% Titania nanoparticles. Figure 1 shows the comparison of viscosity profiles of BPN formulations with PAM based drilling fluid. The formulations BPN-4 and $\mathrm{B} / \mathrm{PAM} / \mathrm{N}$ has same concentration of bentonite, polymer and nanoparticles. It was observed that BPN-4 formulation has viscosity is relatively higher compared to the viscosity of B/PAM/N formulation at all shear rates. Figure 2 shows the comparison of 10 seconds and 10 minutes gel strength of different drilling fluid formulations. The increase in the concentration of associative polymer and Titania nanoparticles results in the increase of gel strength. The highest value of 10 seconds and 10 minutes gel strength was observed for BPN-4 formulation. However, the PAM based drilling formulation at the same composition as BPN-4 has, results in the slightly less value of gel strength.

The less amount of filtrate loss from a drilling fluid over the time of 30 minutes indicates the effectiveness of drilling formulation. The minimum fluid loss was observed for BPN-4 formulation while the PAM based drilling fluid results in the slightly increased fluid loss compared to the BP-4 and BPN-4 formulations as shown in Figure 3. Similarly, the hot rolling dispersion test indicates the effectiveness of drilling fluid formulation that recovers maximum amount of shale cuttings after the hot rolling dispersion experiment as shown in Figure 4. The maximum shale recovery was observed with the BPN-4 drilling fluid formulation, whereas the PAM based drilling fluid showed the shale recovery up to $91 \%$. 
The comparison of BPN-4 and PAM based drilling fluid formulation showed that the BPN-4 formulation has superior viscosity, higher gel strength, minimum fluid loss and the maximum recovery of shale compared to the PAM based drilling fluid. The superior properties of BPN-4 formulation was due to the presence of associative polymer which has hydrophilic as well as hydrophobic moieties. The viscosity increase occurs from the association of the hydrophobic molecules that forms a 3-dimensional network structure when it dissolves in water. The main attractions of these polymers are their significant viscosity enhancement ability compared with the conventional PAM based drilling fluids. The increased viscosity of associative polymer based drilling fluid formulation (BPN-4) also results in superior gel strength, the minimum fluid loss, and maximum recovery of shale cuttings. Whereas, the conventional PAM doesn't have hydrophobic moieties in the polymer structures and therefore lacks in the drilling fluid properties compared to associative polymer based drilling fluid formulations.

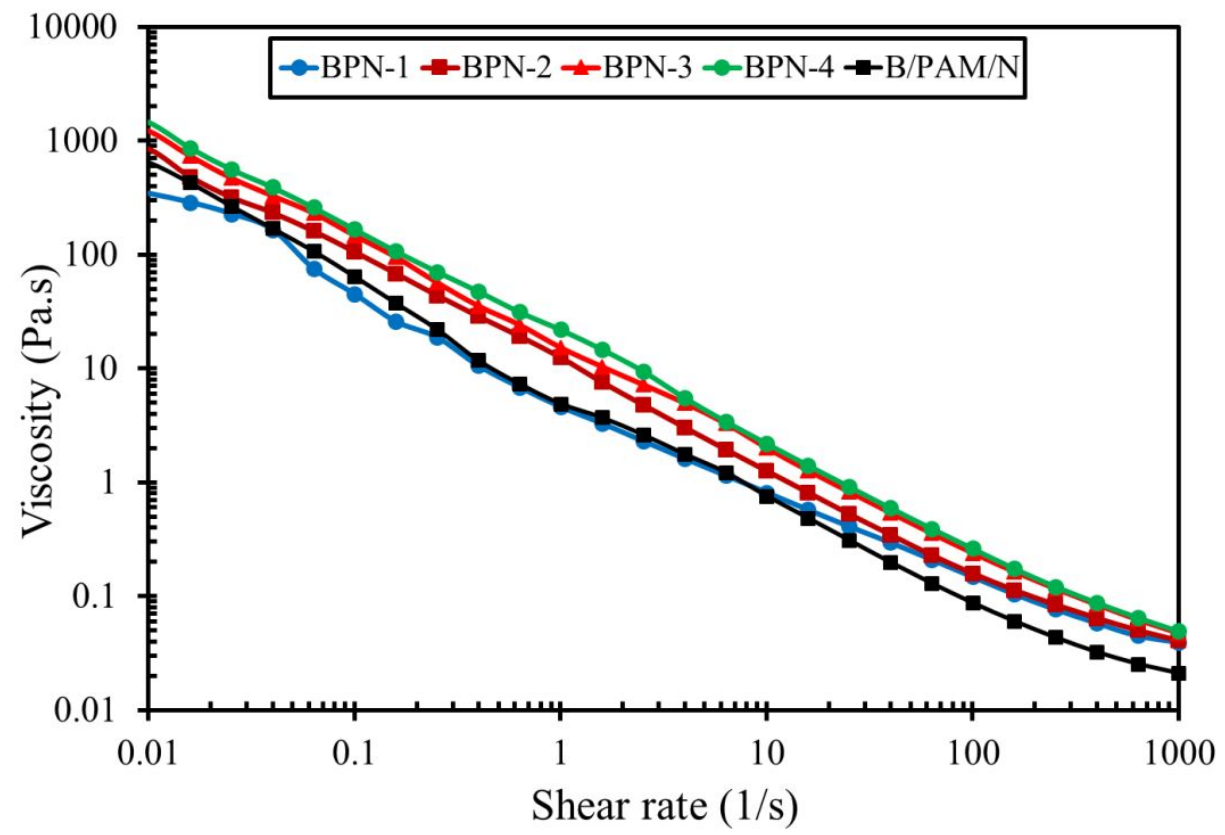

Figure 1. Effect of polymer and nanoparticles concentration on the viscosity profile of drilling fluids and comparison with PAM based drilling fluid 


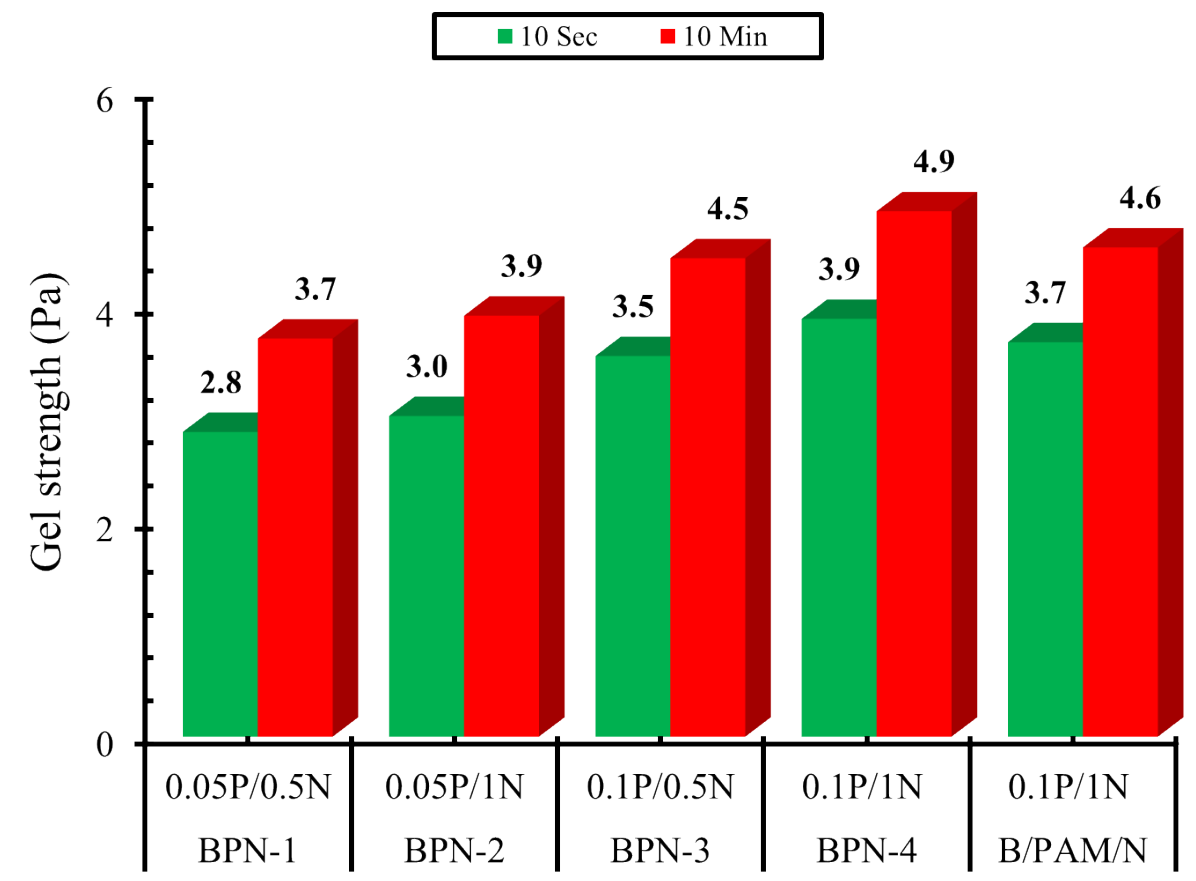

Figure 2. Comparison of gel strengths of BPN formulations with PAM based drilling fluid

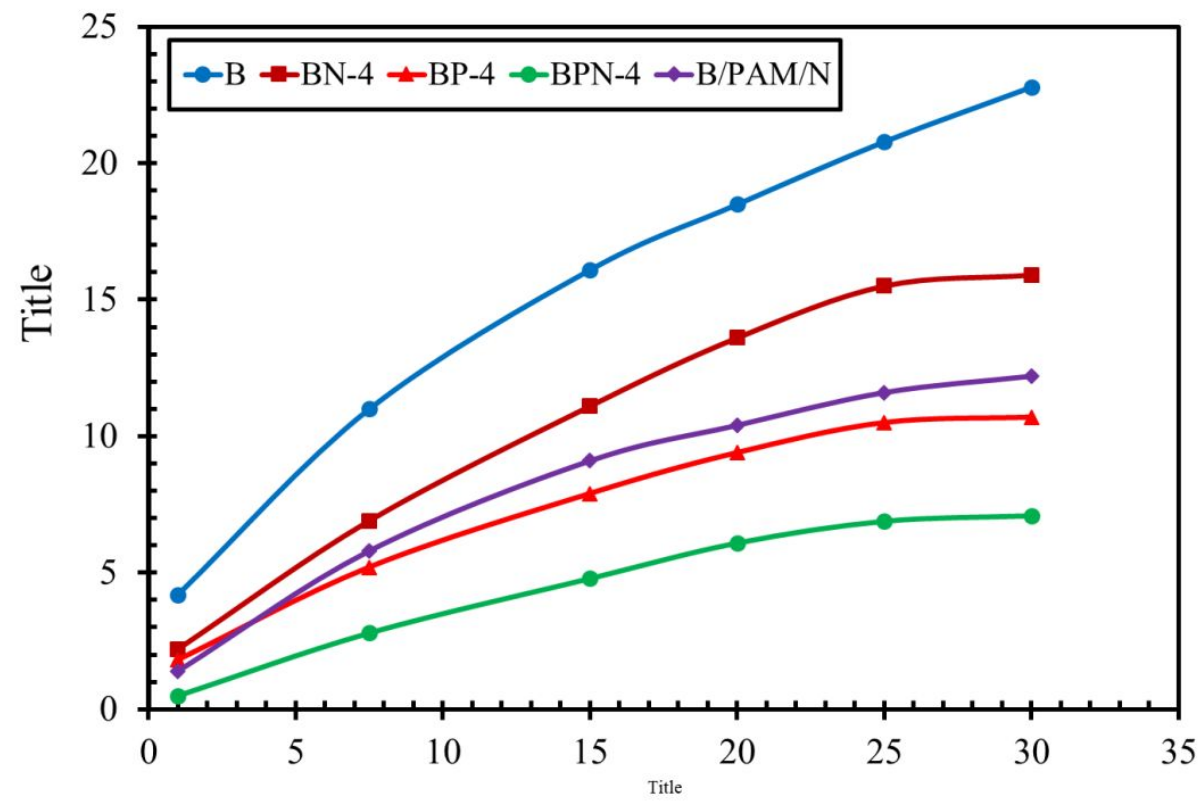

Figure 3. Comparison of filtrate loss of different drilling fluid formulations (B, BN-4, BP-4, BPN-4, B/PAM/N) 


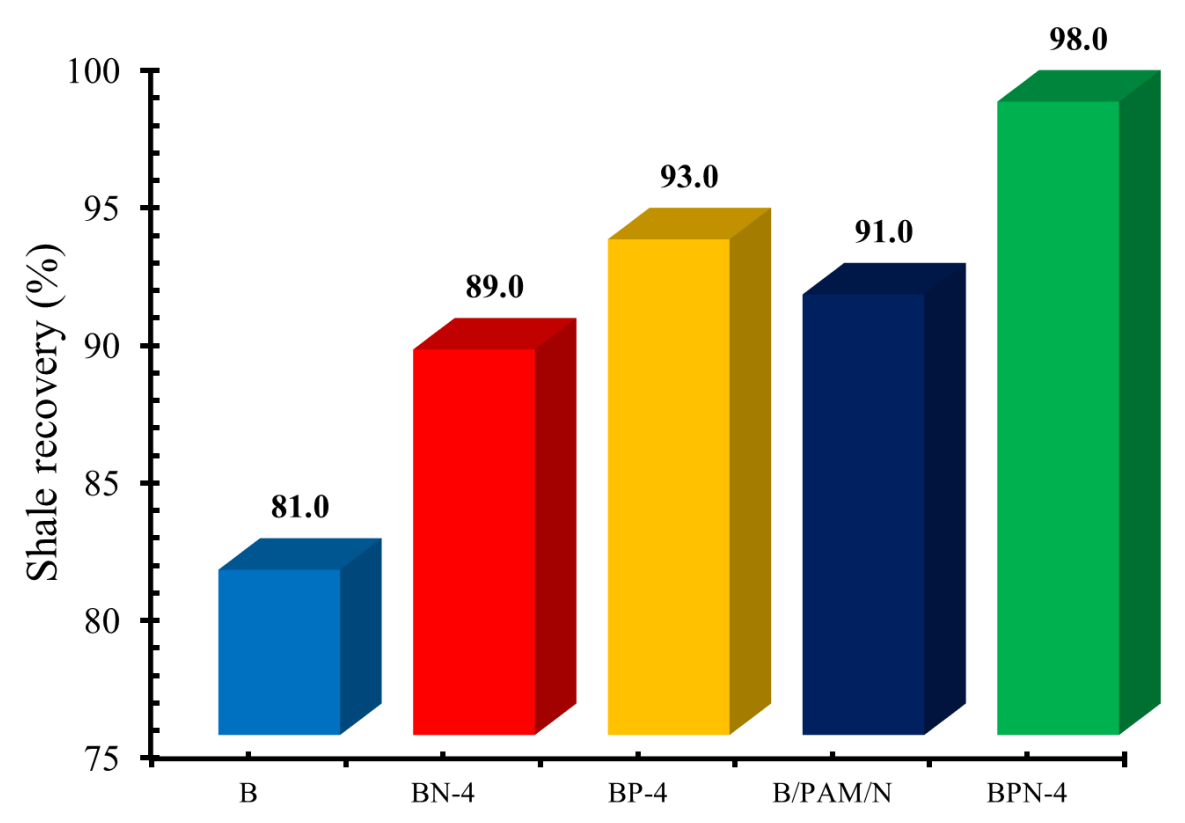

Figure 4. Percentage of shale recovery in the presence of different drilling fluid formulations (B, $\mathrm{BN}-4, \mathrm{BP}-4, \mathrm{BPN}-4, \mathrm{~B} / \mathrm{PAM} / \mathrm{N}$ )

\section{Comparison of rheological properties of BPN formulations at two different temperatures}

Figure 5 shows the comparison of viscosity profiles of BPN formulations at two different temperatures. Figure 5(a) shows the viscosity profiles at $25^{\circ} \mathrm{C}$ and viscosity of BPN formulation increased by increasing the concentration of associative polymer and Titania nanoparticles. The viscosity increase occurs from the association of the hydrophobic moieties in the associative polymer that forms a 3-dimensional network structure when it dissolves in water. The main attractions of these polymers are their significant viscosity enhancement ability compared with the conventional PAM based drilling fluids. The conventional PAM doesn't have hydrophobic moieties in the polymer structures and therefore lacks in the drilling fluid properties compared to associative polymer based drilling fluid formulations. Figure 5(b) shows the viscosity profiles of 
BPN formulation at $50^{\circ} \mathrm{C}$ and it was observed that increasing the temperature results in the decrease in the viscosity of BPN formulation. The decrease in the viscosity was attributed to the uncoiling or breaking of three-dimensional network structure among the polymer chains due to high temperature in the drilling fluid formulation.

(a)

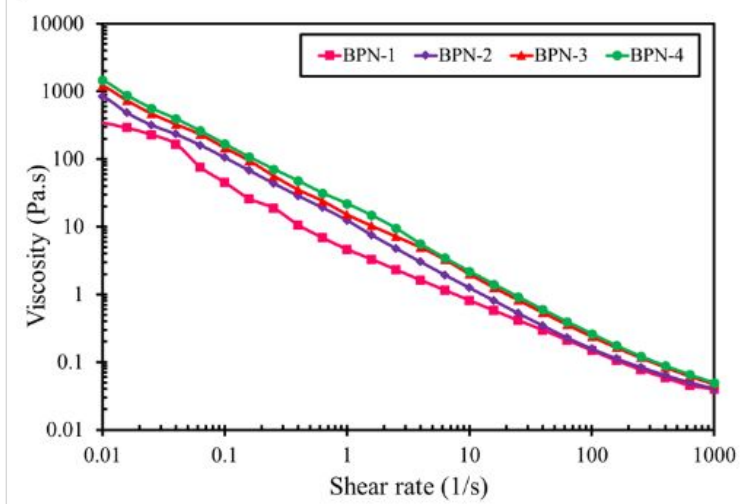

(b)

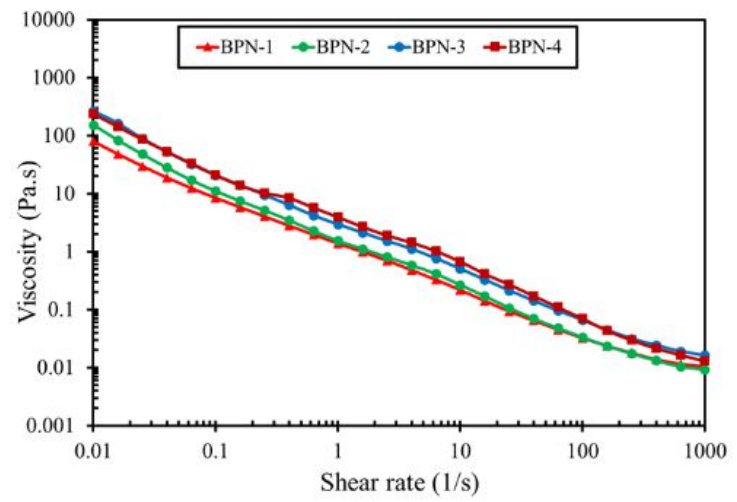

Figure 5. Comparison of viscosity profile at two different temperatures (a) at $25^{\circ} \mathrm{C}$ (b) at $50^{\circ} \mathrm{C}$ 